\title{
A RARE CASE OF SINUS NODE DYSFUNCTION- LYME'S DISEASE
}

\author{
Jayaprakash Nanda Kumaran'1, Anuradha Hariharan², Elayaraja Pallavan ${ }^{3}$ \\ ${ }^{1}$ Assistant Professor, Department of General Medicine, GKMC, Government Royapettah Hospital. \\ ${ }^{2}$ Assistant Professor, Department of General Medicine, GKMC, Government Royapettah Hospital. \\ 3 Postgraduate Student, Department of General Medicine, GKMC, Government Royapettah Hospital.
}

\section{ABSTRACT}

\section{BACKGROUND}

Lyme's disease is a vector-borne disease caused by spirochete, Borrelia burgdorferi that is transmitted by ticks of the Ixodes ricinus complex. A 15-year-old male patient present with c/o fever, giddiness, difficulty in walking and vomiting for 10 days. Vitals normal. ECG shows sinus node dysfunction. 0/E patient having cerebellar dysfunction in the form of dysarthria, swaying of body to left side in straight line walking, dysdiadochokinesia and abnormal finger-to-nose test on left side. CT brain was normal. Serum IgM antibodies for Borrelia burgdorferi was positive. Patient was treated with Inj. Ceftriaxone and C. doxycycline. This case is being reported, because CNS and cardiac involvement in Lyme's disease is rare in India.

\section{KEYWORDS}

Lyme's Disease, Borrelia, Cerebellum, Sinus Node, Disseminated Infection, Arthritis, Erythema Migrans, CSF Analysis.

HOW TO CITE THIS ARTICLE: Kumaran JN, Hariharan A, Pallavan E. A rare case of sinus node dysfunction- Lyme's disease. J. Evolution Med. Dent. Sci. 2017;6(22):1829-1830, DOI: 10.14260/Jemds/2017/403

\section{BACKGROUND}

Lyme's disease was recognised as a separate entity in 1976 because of a geographic cluster of children in Lyme, Connecticut who were thought to have juvenile rheumatoid arthritis. It became apparent that Lyme disease was a multisystem illness that affected primarily the skin, nervous system, heart and joints. Epidemiological studies of patients with erythema migrans implicated certain Ixodes ticks as vector of the disease. Lyme's disease is now the most common vector borne infection in United States and Europe. Possible manifestation of infection includes secondary annular skin lesions, meningitis, cranial neuritis, A-V nodal block and migratory musculoskeletal pain. After the period of latent infection, intermittent or persistent arthritis or acrodermatitis may develop.

\section{Case Report}

A 15 years old male patient admitted with c/o fever, slurring of speech, swaying of body while walking, vomiting and joint pain for 10 days. Patient was apparently normal 2 weeks back. Then he developed fever, which is low-grade intermittent, not $\mathrm{a} / \mathrm{w}$ chills and rigor. Not $\mathrm{a} / \mathrm{w}$ seizure, icterus, facial deviation, weakness of limbs. No history suggestive of similar illness in the past. Not a smoker, not an alcoholic.

O/E patient was conscious, oriented, afebrile, not dyspnoeic, not anaemic, not icteric. No cyanosis, no clubbing, no pedal oedema, no generalised lymphadenopathy or no rashes. Erythema migrans seen in right infraaxillary region. CVS: S1, S2 heard. No murmur. RS: NVBS. No added sound. P/A: Soft. No organomegaly. CNS: Higher function, cranial nerves, spino motor system, sensory nervous system, autonomic nervous system, spine and cranium are normal.

Financial or Other, Competing Interest: None.

Submission 31-01-2017, Peer Review 02-03-2017,

Acceptance 09-03-2017, Published 16-03-2017.

Corresponding Author:

Dr. Jayaprakash Nanda Kumaran,

\#4/2, Kambar Street, Ponni Nagar, Karambakkam,

Porur, Chennai-600116.

E-mail: jayaprakash.nandakumaran@rediffmail.com

DOI: $10.14260 /$ jemds $/ 2017 / 403$

\section{(c) $($ ) $\$$}

Cerebellum: dysfunction present in the form of dysarthria, swaying of body to left side in straight line walking, dysdiadochokinesia and abnormal finger nose test on left side. BP: 110/72 mmHg, PR- 82/min, irregularly irregular in character. Normal volume. Clinical diagnosis was made as acute cerebellitis? post-viral aetiology.

Initial investigation: CBC: Hb- 13.2 gm, TC- 7200 cells/cu.mm, DC- P48 L52 E0, Platelet- 2.16 lakh/cu.mm, ESR$1 / 2$ hour $30 \mathrm{~mm}, 1$ hour $-55 \mathrm{~mm}$. RBS- $75 \mathrm{mg} / \mathrm{dL}$, urea- 26 $\mathrm{mg} / \mathrm{dL}$, cr- $0.6 \mathrm{mg} / \mathrm{dL}$, sr. protein- $6.3 \mathrm{gm}$, albumin- $3.5 \mathrm{gm}$, globlin- $2.8 \mathrm{gm}$, bilirubin- $0.8 \mathrm{mg} / \mathrm{dL}$. Urine- albumin, sugarnil; deposit-0-1 pus cells, 1-2 epithelial cells. Viral Markers: HSV, EBV, CMV, JE- Negative. CSF analysis: No cells seen, protein- $45 \mathrm{mg} / \mathrm{dL}$, sugar- $105 \mathrm{mg} / \mathrm{dL}, \mathrm{C} / \mathrm{S}-$ no growth. CXR PA view- NAD, USG Abdomen- normal study. ECG- shows sinus node exit block. 24 hours Holter monitoring of ECG done. It shows sinus node dysfunction. ${ }^{1}$

We evaluated further as infective cause for both cardiac and CNS involvement. Serum sample sent for IgM antibodies for Borrelia burgdorferi. It becomes positive. Based on clinical examination and investigation, a diagnosis of Lyme's disease was made and patient was started on oral doxycycline $100 \mathrm{mg}$ bd and Inj. ceftriaxone $500 \mathrm{mg}$ IV bd daily for 2 weeks. C. doxycycline $100 \mathrm{mg}$ bd continued for next 2 weeks. Patient's condition clinically improved.

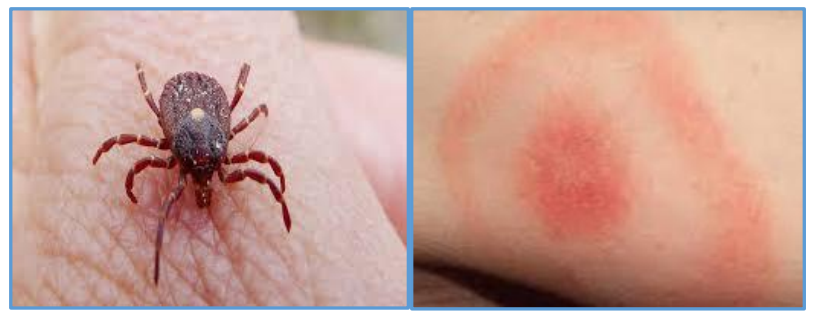

Ixodes Tick Erythema Migrans 


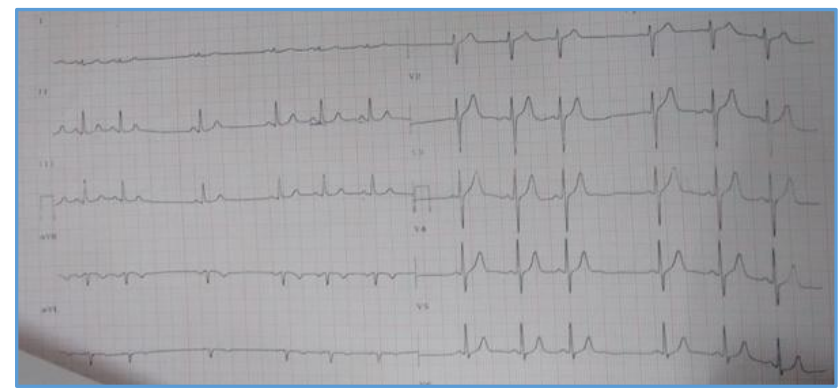

ECG-Sinus Node Exit Block

\section{DISCUSSION}

Lyme's disease is a vector-borne disease caused by a spirochete, Borrelia burgdorferi that is transmitted by ticks of the Ixodes ricinus complex. Incubation period 3 - 32 days.

Clinical manifestation: Stage 1 [early infection], after the incubation period erythema migrans usually begin as red macule or papule at the site of the tick bite that responds slowly to form a large annular lesion. Erythema migrans can be located anywhere, thigh, groin and axilla.

Stage II: B. burgdorferi often spreads haematogenously to many sites within days or weeks after the onset of erythema migrans. Skin involvement accompanied by severe headache, mild stiffness of neck, fever, chills, migratory musculoskeletal pain, arthralgia and profound malaise and fatigue. Symptoms suggestive of meningeal irritation may develop early in Lyme's disease when EM is present, but usually are not a/w CSF pleocytosis or objective neurological deficit after several weeks or months; $15 \%$ of untreated patients develop frank neurological abnormalities including meningitis, subtle encephalitis, cranial neuritis, motor or sensory radiculopathy, mononeuritis multiplex, cerebellar ataxia or myelitis.

$8 \%$ of patients develop cardiac involvement is a fluctuating degree of $\mathrm{A}-\mathrm{V}$ block. $^{2}$ Some patients have more diffuse cardiac involvement including echocardiographic changes indicative of acute myopericarditis, ${ }^{3} \mathrm{LV}$ dysfunction, ${ }^{4}$ cardiomegaly or fatal pericarditis.
Stage III: Month after the onset of infection, $60 \%$ of patients develop arthritis who have not received antibiotics. Raised WBC with synovial biopsy shows signs of inflammation.

Post Lyme syndrome: Despite antibiotic therapy $10 \%$ of patients continue to have subjective pain, neurocognitive manifestations or fatigue symptoms. These symptoms usually improve and resolve within months, but may last for years. Currently, no evidence indicates that persistent subjective symptoms after recommended courses of antibiotic therapy are caused by active infection.

\section{Treatment}

1. Skin, joint and heart [A-V block 1 and 2 degree]- oral antibiotics for 14 days. Doxycycline, amoxicillin, cefuroxime axetil, erythromycin.

2. Nervous system involvement- IV antibiotics 14 - 28 days. Cardiac involvement ${ }^{5}$ - IV antibiotics 28 days f/b oral antibiotics when patient is no longer in high-degree $\mathrm{AV}$ block. [IV antibiotics- ceftriaxone, cefotaxime, $\mathrm{Na}$ penicillin G].

\section{REFERENCES}

[1] Steere AC, Batsford WP, Weinberg M, et al. Lyme carditis: cardiac abnormalities of lyme disease. Ann Intern Med 1980;93(1):8-16.

[2] Van der Linde MR, Crijns HJ, de Koning J, et al. Range of atrioventricular conduction disturbances in lyme borreliosis: a report of 4 cases and review of other published reports. Br Heart J 1990;63(3):162-8.

[3] Vlay SC, Dervan JP, Elias J, et al. Ventricular tachycardia associated with lyme carditis. Am Heart J 1991;121(5):1558-60.

[4] Cary NR, Fox B, Wright DJ, et al. Fatal lyme carditis and endodermal heterotopia of the atrioventricular node. Postgrad Med J 1990;66(772):134-6.

[5] Barr JR, Pollock P. Inclusion cyst of the myocardium in a patient with complete heart block. Can Med Assoc J 1968;98(1):52-3. 